\title{
Neutralization of Naja kaouthia Venom Induced Toxicity and Stress Response by Vitex negundo-Gold Nanoparticle (VN- GNP) in Experimental Animal Model
}

\begin{abstract}
Keywords: Naja ka outhia; Sna ke venom; Venom toxic ity; Venomstress; Gold nanoparticle; Vitex negundo

Abstract

Snake bite is a neglected tropical disease and a socio-medica problem in India. Anti-snake venom serum (ASVS), the only available treatment possesses several limitations. Search for altemative treatment against snake bite is a long challenge to the researcher In the present study, neutralization of Naja kaouthia venom (NKV) induced acute toxicity, acute stress and cytokine response were done with herbal (Vitex negundo) gold nanoparticle (VN-GNP) in experimental animal model. VN-GNP was prepared by reducing gold salt using aqueous root extract of Vitex negundo (VN) and its physico-chemical characterization was done by DLS (size and zeta potential), FIR and TEM. Swiss male albino mice were taken in group 1- sham control, group 2- NKV control, group 3- ASVS treated, group 4- GNP treated, group 5- VN treated and group 6- VN-GNP treated. Bioc hemic al parameters, unina ry parameters, a ntioxida nt parameters, cytokines and histology of liver and kidney tissues were done. NKV treatment in group 2 mice showed significant changes in biochemical parameters (CK, LDH, GPT, GOT, Y-GT, ACP, ALP), urinary parameters (calcium, phosphate), stress parameters (SOD, GSH, catalase, LPO) and cytokines (serum IL-10, IL-17, IL-1 $\beta$ and TNFa) as compared with group 1 (sham control) animals. VN-GNP treatment in group 6 mice significantly neutralized NKV induced toxicity/stress/cytokine response as compared with group 2 mice. Degree of NKV neutralization was VN-GNP>VN>ASVS, thus indicating VN-GNP may have advantage over ASVS for NKV induced organ toxic ity and stress neutralization in experimental a nimal model and wa rants further detailed studies.
\end{abstract}

\section{Introduction}

Snake envenomation is very common in tropical countries including India. Most of the snake bite and mortality occurs in Asia, Southeast and sub-Saharan Africa and India has the highest mortality rate [1]. World Health Organization (WHO) has declared snake bite as a neglected tropical disease. In Indian rural areas, approximately 25,000 people die every year due to snake bite and worldwide the number has been increased up to 40,000 annually [2]. The common venomous snakes found in India are Indian cobra (Naja naja), Common krait (Bungarus caeruleus), Russell's viper (Daboia russelii), Saw-scaled viper (Echis carinatus) which cause a high morbidity and mortality. The Indian monocellate cobra Naja kaouthia (family Elapidae) is prevalent in the entire eastern and north-eastern parts of India and is responsible for a large number of snakebite cases [3]. According to WHO, Naja kaouthia belongs to category 1 of

\section{Journal of} Toxins

Kalyani Saha ${ }^{1}$, Sourav Ghosh ${ }^{1}$, Susmita Ghosh ${ }^{1}$ Subir Chandra Dasgupta ${ }^{2}$, Aparna Gomes ${ }^{3}$ and Antony Gomes ${ }^{1 *}$

${ }^{1}$ Department of Physiology, Laboratory of Toxinology \& Experimental Pharmacodynamics, University of Calcutta

92, APC Road, Kolkata 700009, India

${ }^{2}$ Department of Zoology, Maulana Azad College, Kolkata, India Indian Institute of Chemical Biology, Drug Development/ Diagnostics \& Biotechnology Division, Indian Institute of Chemical Biology, Raja S C Mullick Road - 700 032, Kolkata, India

*Address for Correspondence

Antony Gomes, Department of Physiology, Laboratory of Toxinology \& Experimental Pharmacodynamics, University of Calcutta 92, APC Road, Kolkata 700009, India, Tel: 91-33-23508386/6387/6396/1397 (Extn: 229); Fax: 91-33-2351-9755/2241-3288; E-mail: agomescu@gmail.com

Submission: 03 June 2015

Accepted: 26 August 2015

Published: 31 August 2015

Copyright: (c) 2015 Saha K, et al. This is an open access article distributed under the Creative Commons Attribution License, which permits unrestricted use, distribution, and reproduction in any medium, provided the original work is properly cited.

venomous snakes. Symptoms of Naja kaouthia envenomation include general neurotoxicity leading to flaccid paralysis, severe hypertension, coagulopathy and death by respiratory failure. Naja kaouthia venom (NKV) exhibits phospholipase $\mathrm{A}_{2}$ activity, indirect hemolysis, myotoxic activities, weak proteolytic and direct hemolytic activities [4]. The only available treatment of snakebite is anti-snake venom serum (ASVS) which has many side effects (anaphylactic shock, serum sickneness, pyrogenicity, etc.) and limitations (Cost factor, less effective, dose problem, expiry, etc) [5-7]. Moreover, ASVS does not provide protection against organ damages caused by snake envenomation [8]. Stress produced by snake envenmation is an important issue that has been neglected and there is no antidote to manage the venom induced stress in patients. Envenomation induced stress leads to severe complications in snake bite victims and ASVS is of no value in the management of stress [9].

In Ayurveda, the traditional medicinal system of India, many herbs and shrubs including Vitex negundo (VN) have been mentioned having anti-snake venom activity [1]. VN is a woody, aromatic shrub found in Afghanistan, India, Pakistan, Sri Lanka, Thailand, Malaysia, eastern Africa and Madagascar. In the southern parts of Tamil Nadu, India, VN has been used as antidote against Cobra venom for many years [10]. Scientific evaluation of this shrub has already proved to be effective against Cobra venom. Alam and Gomes reported the anti-inflammatory, anti-Vipera russellii venom activity and antiNaja kaouthia venom activity of VN root extract [11]. Durairaj et al. reported the anti-viper and anti-Naja kaouthia venom activity of VN leaf extract [12]. From the introduction of Rasa sastra in the Ayurveda, the use of combination of natural products and metals was a common practice against several ailments. Ayurvedic processing's of metal and herb combinations transform the metal in nanoscale size, thus turns it more effective in treating diseases by increasing the efficacy of the herb [13]. Earlier from this laboratory, it has been shown that gold nanoparticle conjugated with 2-hydroxy- 4-methoxy benzoic acid (HMBA) isolated from the root extract of Hemidesmus 
Citation: Saha K, Ghosh S, Ghosh S, Dasgupta SC, Gomes A, et al. Neutralization of Naja kaouthia Venom Induced Toxicity and Stress Response by Vitex negundo-Gold Nanoparticle (VN-GNP) in Experimental Animal Model. J Toxins. 2015;2(1):8.

ISSN: 2328-1723

indicus, increased the neutralizing effects of snake venom in animal models [14]. The present study was focused on the synthesis of gold nanoparticle using aqueous root extract of Vitex negundo, its physicochemical characterization and NKV neutralization efficacy against toxicity, stress was evaluated in experimental animal model.

\section{Materials and Methods}

\section{Venom}

Lyophilized Naja kaouthia venom (NKV) was commercially collected from Calcutta Snake Park, Kolkata, India and preserved in desiccators at $4{ }^{\circ} \mathrm{C}$ in an amber coloured glass vial until further use. The snake venom was dissolved in ultrapure water, kept at $2-8{ }^{\circ} \mathrm{C}$ for $18 \mathrm{~h}$ and centrifuged at $3000 \mathrm{rpm}$ for $10 \mathrm{~min}$. The supernatant was used as venom and kept at $2-8{ }^{\circ} \mathrm{C}$ until further use. The venom concentration was expressed in terms of dry weight $(\mathrm{mg} / \mathrm{ml}, \mathrm{w} / \mathrm{v})$.

\section{Root extract of Vitex negundo}

Dry root of Vitex negundo (VN) was obtained commercially from M/s united Chemical and Allied Products, Kolkata, India. 2 g of dry root powder was dissolved in $20 \mathrm{ml}$ of double distilled water for 48 hour at $2-8^{\circ} \mathrm{C}$. Then, it was centrifuged and supernatant was collected and dry weight was measured. The extract was expressed as in term of dry weight $(\mathrm{mg} / \mathrm{ml}, \mathrm{w} / \mathrm{v})$

\section{Preparation of Vitex negundo gold nanoparticle (VN-GNP)}

$45 \mathrm{ml}$ of ultrapure water was heated to $80^{\circ} \mathrm{C}$ and stirred at 550 rpm. $1.25 \mathrm{ml}$ of $10 \mathrm{mM} \mathrm{HAuCl}$ was added to it with continuous stirring. $5 \mathrm{ml}$ of VN having $17 \mathrm{mg}$ dry weight was added to it, stirred continuously for $30 \mathrm{~min}$. After the formation of gold nanoparticle (VN-GNP), it was centrifuged at $30000 \mathrm{rpm}$ for $30 \mathrm{~min}$ and was resuspended in ultrapure water.

\section{Charectarization of Vitex negundo gold nanoparticle (VN- GNP)}

Dynamic light scattering (hydrodynamic diameter and zeta potential) of VN-GNP was done using Beckmann Coulter Delsa Nano C TM. The FTIR spectrum was obtained using Nicolet 6700 FTIR. The size, shape and morphology of VN-GNP were determined by transmission electron microscope image using JEOL JEM 2100.

\section{Animals used and experimental design}

Animal ethical clearance was obtained before commencement of experiment (clearance no. IAEC/Revised Proposal/AG01/2012 dt.01.02.2013). Swiss male albino male mice ( $20 \pm 2$ gm) aged 8 -9 weeks were obtained from authorized animal suppliers of University of Calcutta. The animals were kept in polypropelene cages in a well-ventilated room. They were acclimatized and maintained in a controlled environment (temperature: $25 \pm 2{ }^{\circ} \mathrm{C}$, humidity: $60 \pm 5 \%$ and $12 \mathrm{~h}$ light-dark cycle). Food and water was provided ad libitum. The animals were allowed 10 days to adapt in their environment. All experimental protocols described in this study were approved by the animal ethics committee, University of Calcutta and were in accordance with the guideline of the Committee for the Purpose of Control and Supervision of Experiments on Animal (CPCSEA), Government of India.

Animals were divided into six groups $(n=6)$ : Group 1-sham control, Group 2- NKV control, Group 3- ASVS treated, Group 4GNP treated, Group 5- VN treated and Group 6- VN-GNP treated. NKV $(20 \mu \mathrm{g} / 20 \mathrm{gm} / \mathrm{i} . \mathrm{m})$ was injected in Group 2, 3, 4, 5 and 6 animals. After $2 \mathrm{~h}$ ASVS (100 $\mu$ g, trade name: Duvenin-FD, batch no: 012004, expiry date: March 2018), GNP $(100 \mu \mathrm{l}), \mathrm{VN}(100 \mu \mathrm{l})$ and VN-GNP $(200 \mu \mathrm{l})$ were injected (i.v.) in Gr. 3, 4, 5 and 6 animals, respectively. The ED50 value of ASVS, VN and VN-GNP were $200 \mu \mathrm{g}, 200 \mu \mathrm{l}$ and $400 \mu \mathrm{l}$ respectively, which neutralize 1 MLD dose (i.m) of NKV i.e. $40 \mu \mathrm{g}$. In the present study, $1 / 2$ MLD (i.m.) dose of NKV $(20 \mu \mathrm{g})$ was used, therefore $1 / 2$ ED50 values of ASVS, VN and VN-GNP were used in the present study. After $24 \mathrm{~h}$, urine, blood (collected from hepatic portal vein) and tissues (liver, kidney) were collected from all groups of animals.

\section{Neutralization of NKV-induced toxicity markers}

$\mathrm{NKV}$-induced changes in biochemical parameters were evaluated by assaying serum lactate dehydrogenase (LDH), creatine kinase (CK), serum glutamic pyruvic transaminase (SGPT), serum glutamic oxaloacetic transaminase (SGOT), serum $\gamma$-glutamyltransferase $(\gamma$ GT), serum acid phosphatase (ACP), serum alkaline phosphatase (ALP), serum creatinine, serum urea and urinary calcium using biochemical kit (Merck, India) and urinary phosphate after Fiske and Subbarow [15]. Serum cytokines (IL-1 $\beta$, TNF- $\alpha$, IL-10 \& IL17) were estimated by using ELISA kit (R\&D, USA) according to manufacturer's instruction.

\section{Neutralization of NKV-induced stress markers}

NKV-induced stress and its neutralization by VN-GNP was evaluated by assaying reduced glutathione, superoxide dismutase, lipid peroxidation and catalase. Serum reduced glutathione was estimated after Ellman expressed as $\mu \mathrm{M} / \mathrm{mg}$ protein, serum superoxide dismutase was estimated after Pryor expressed as IU/ mg protein, serumlipid peroxidation was estimated after Buege and Aust expressed as MDA/mg protein [16-18]. Catalase $(\mu \mathrm{M} / \mathrm{mg}$ hemoglobin) was estimated from RBC lysate after Beers and Sizer [19]. Mice RBC lysate was prepared from heparinised blood after centrifuged for $10 \mathrm{~min}$ at $3000 \mathrm{rpm}$ and $1 \%$ solution of packed cell volume was used. Serum protein was estimated after Lowry et al. [20].

\section{NKV induced histopathological changes}

$\mathrm{NKV}$-induced organ toxicity and the effect of VN-GNP treatment was evaluated through histopathological studies of liver and kidney tissues. The tissues were collected from all animal groups, fixed in $10 \%$ buffered formalin for $24 \mathrm{~h}$. Tissues were then dehydrated in graded $(50-100 \%)$ ethanol followed by clearing in xylene. Paraffin $\left(56{ }^{\circ} \mathrm{C}-58{ }^{\circ} \mathrm{C}\right.$ ) embedding was done at $58 \pm 1{ }^{\circ} \mathrm{C}$ for $4 \mathrm{~h}$, followed by paraffin block preparation. Tissue sections of $5 \mu \mathrm{m}$ were cut using a rotary microtome (Weswox model MT-1090, India). Paraffin sections were deparaffinised with xylene, stained with haematoxyiln-eosin, followed by mounting in DPX with a cover slip. Histological changes were observed with a bright field microscope (Motic, Germany) and photographs were captured using Motic software (Motic Images Plus 2.0 software).

\section{Statistical analysis}

Statistical analysis was done using one way ANOVA $(n=6)$. Values were expressed as mean \pm standard error of mean, $\mathrm{P}<0.05$ was considered as statistically significant. 
Citation: Saha K, Ghosh S, Ghosh S, Dasgupta SC, Gomes A, et al. Neutralization of Naja kaouthia Venom Induced Toxicity and Stress Response by Vitex negundo-Gold Nanoparticle (VN-GNP) in Experimental Animal Model. J Toxins. 2015;2(1):8.

\section{Results}

\section{Formation and characterization of Vitex negundo gold} nanoparticle (VN-GNP)

VN-GNP was prepared by using the reducing property of VN and was found to be violet in colour. It was stable for 30 days at room temperature $\left(25 \pm 2{ }^{\circ} \mathrm{C}\right)$ and 60 days at $2-8{ }^{\circ} \mathrm{C}$. Dynamic light scattering data showed that there was formation of monodispersed nanoparticles with hydrodynamic diameter of about $80-90 \mathrm{~nm}$ with poly-dispersity index 0.309 (Figure 1). Zeta potential of VN-GNP was found to be $-13.11 \mathrm{mV}$ which indicated stability of the herbal gold nanoparticle (Figure 2). FTIR analysis of the spectra revealed the inclusion of the post lanthanide late transitional element gold as a part of the complex. The stretching of the curve at $3423.26 \mathrm{~cm}^{-1}$ revealed the presence of free $-\mathrm{OH}$ or $-\mathrm{NH}$ group with $-\mathrm{OH}$ in the solution. There was another stretching at the position of $1644.86 \mathrm{~cm}^{-1}$ which indicated the presence of amino acids, acid or carbohydrates (Figure 3). Transmission electron microscopy showed the shape of VN-GNP spherical with particle size of 25-40 nm (Figure 4).

\section{Neutralization of NKV-induced toxicity markers by VN- GNP}

NKV treatment in group 2 animals caused significant $(\mathrm{P}<0.05)$ increase in serum lactate dehydrogenase (LDH) when compared to group 1 sham control animals. Treatment with ASVS and GNP caused no significant change in serum LDH when compared to group 2 NKV-treated animals. Treatment with VN and VN-GNP caused significant $(\mathrm{P}<0.05)$ decrease in serum $\mathrm{LDH}$ level when compared to group $2 \mathrm{NKV}$-induced animals. The percentage decrease in serum

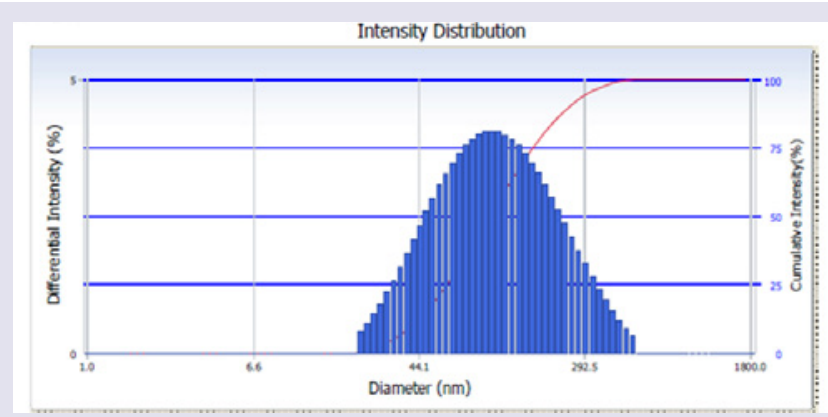

Figure 1: Dynamic light scattering (DLS) of VN-GNP.

Hydrodynamic diameter of VN-GNP was found to be $80-90 \mathrm{~nm}$ with polydispersity index 0.309 .

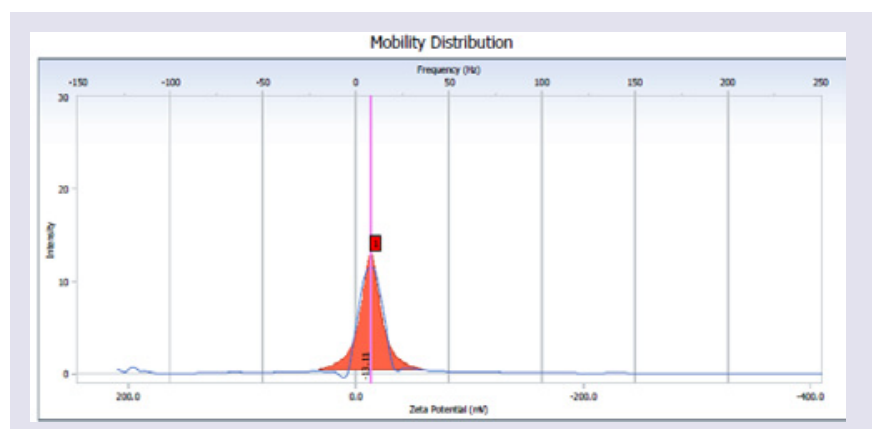

Figure 2: Zeta potential plot of VN-GNP.

Zeta potential of VN-GNP solution was found to be $-13.11 \mathrm{mV}$.

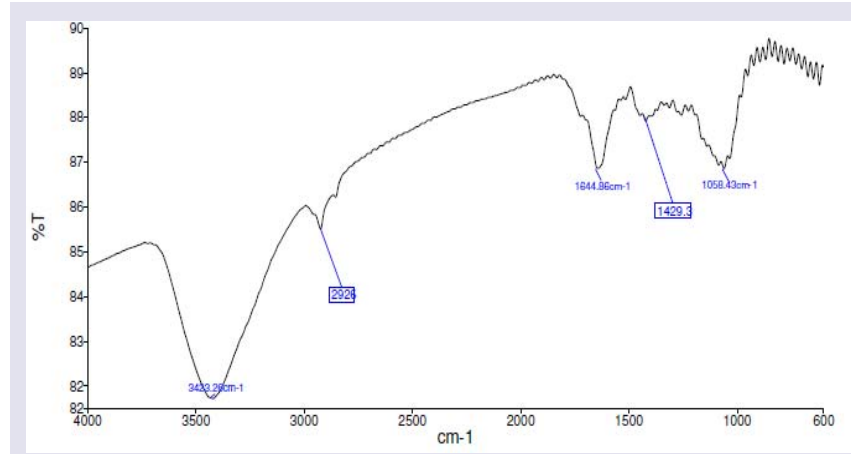

Figure 3: FTIR spectrum of VN-GNP.

FTIR of VN-GNP showed the presence of herbal compounds and gold nanoparticle in the solution.

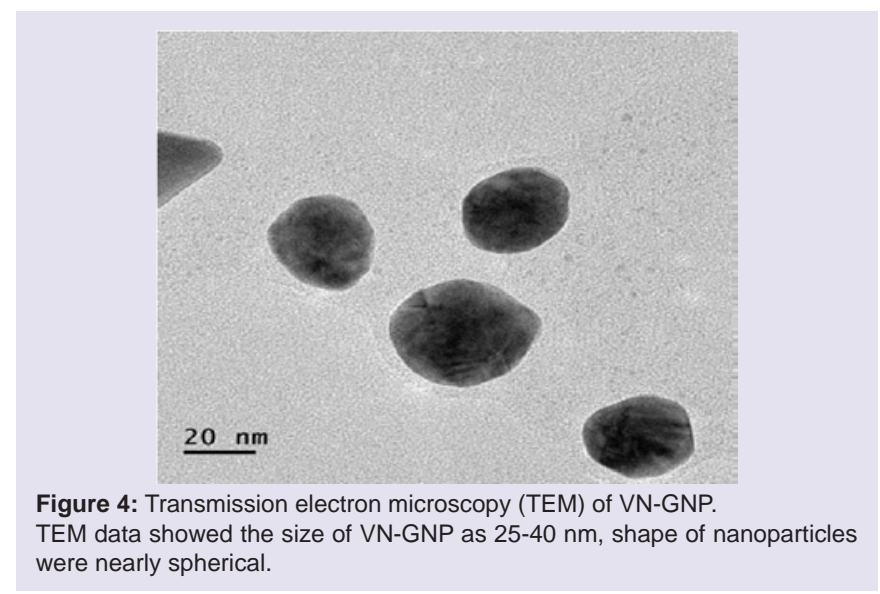

LDH level in VN and VN-GNP- treated animals were $49 \%$ and $65 \%$, respectively (Table 1).

NKV treatment in group 2 animals caused significant $(\mathrm{P}<0.05)$ increase in serum creatine kinase (CK) when compared to group 1 sham control animals. Treatment with ASVS and GNP caused no significant change in serum CK when compared to group $2 \mathrm{NKV}$ treated animals. Treatment with VN and VN-GNP caused significant $(\mathrm{P}<0.05)$ decreased serum $\mathrm{CK}$ level when compared to group $2 \mathrm{NKV}$ induced animals. The percentage decrease in serum CK level in VN and VN-GNP- treated animals were $54 \%$ and $72 \%$, respectively (Table 1).

NKV in group 2 animals caused significant $(\mathrm{P}<0.05)$ increase in serum glutamic pyruvic transaminase (SGPT) when compared to group 1 sham control animals. Treatment with ASVS and GNP caused no significant change in SGPT when compared to group 2 NKV-treated animals. Treatment with VN and VN-GNP caused significant $(\mathrm{P}<0.05)$ decrease in SGPT level when compared to group $2 \mathrm{NKV}$-induced animals. The percentage decrease in SGPT level in VN and VN-GNP-treated animals were $20 \%$ and $41 \%$, respectively (Table 1).

NKV in group 2 animals caused significant $(\mathrm{P}<0.05)$ increase in serum glutamic oxaloacetic transaminase (SGOT) when compared to group 1 sham control animals. Treatment with ASVS and GNP caused no significant change in SGOT when compared to group 2 NKV-treated animals. Treatment with VN and VN-GNP caused 
Citation: Saha K, Ghosh S, Ghosh S, Dasgupta SC, Gomes A, et al. Neutralization of Naja kaouthia Venom Induced Toxicity and Stress Response by Vitex negundo-Gold Nanoparticle (VN-GNP) in Experimental Animal Model. J Toxins. 2015;2(1):8.

Table 1: Effect of VN-GNP on serum and urinary parameters in NKV induced Swiss male albino mice. Gr.1, sham control, Gr.2 NKV control, Gr.3 ASVS treated, Gr.4 GNP treated Gr.5 VN treated, Gr.6 VN-GNP treated .Values were expressed as mean \pm standard error of mean ( $\mathrm{n}=6$ ), statistical analysis was done with one way ANOVA, ${ }^{P} \mathrm{P}<0.05$ when compared to sham control group, ${ }^{*} \mathrm{P}<0.05$ when compared to NKV control group.

\begin{tabular}{|c|c|c|c|c|c|c|c|c|c|c|c|}
\hline Group & $\begin{array}{l}\text { Serum } \\
\text { LDH } \\
\text { (U/L) }\end{array}$ & $\begin{array}{l}\text { Serum } \\
\text { CK } \\
\text { (U/L) }\end{array}$ & $\begin{array}{l}\text { Serum } \\
\text { GPT } \\
\text { (U/L) }\end{array}$ & $\begin{array}{l}\text { Serum } \\
\text { GOT } \\
\text { (U/L) }\end{array}$ & $\begin{array}{l}\text { Serum } \\
\text { YGT (U/L) }\end{array}$ & $\begin{array}{l}\text { Serum } \\
\text { ACP } \\
\text { (U/L) }\end{array}$ & $\begin{array}{l}\text { Serum } \\
\text { ALP } \\
\text { (U/L) }\end{array}$ & $\begin{array}{l}\text { Serum } \\
\text { Urea } \\
\text { (mg/dl) }\end{array}$ & $\begin{array}{l}\text { Serum } \\
\text { Creatinine } \\
\text { (mg/dl) }\end{array}$ & $\begin{array}{l}\text { Urinary } \\
\text { Calcium } \\
\text { (mg/dl) }\end{array}$ & $\begin{array}{l}\text { Urinary } \\
\text { Phosphorous } \\
\text { (mg/dl) }\end{array}$ \\
\hline Gr.1 & $149.22 \pm 0.14$ & $12.74 \pm 0.80$ & $27.21 \pm 2.45$ & $19.21 \pm 0.23$ & $2.55 \pm 0.03$ & $1.46 \pm 0.53$ & $114.65 \pm 0.21$ & $25.27 \pm 0.66$ & $0.26 \pm 0.04$ & $1.68 \pm 0.05$ & $0.62 \pm 0.08$ \\
\hline Gr.2 & $512.08 \pm 0.32^{\#}$ & $53.21 \pm 0.11^{\#}$ & $82.21 \pm 0.22^{\#}$ & $96.25 \pm 0.34^{\#}$ & $22.25 \pm 0.13^{\#}$ & $7.27 \pm 0.25^{\#}$ & $189.65 \pm 0.64^{\#}$ & $32.60 \pm 0.75$ & $0.35 \pm 0.03$ & $2.56 \pm 0.12^{\#}$ & $1.50 \pm 0.51^{\#}$ \\
\hline Gr.3 & $496.44 \pm 0.11$ & $52.08 \pm 0.87$ & $78.76 \pm 0.90$ & $94.55 \pm 0.59$ & $19.98 \pm 0.31$ & $6.80 \pm 0.05$ & $186.90 \pm 1.20$ & $36.45 \pm 0.32$ & $0.32 \pm 0.06$ & $2.50 \pm 0.04$ & $1.42 \pm 0.43$ \\
\hline Gr.4 & $506.11 \pm 0.65$ & $56.70 \pm 0.67$ & $80.87 \pm 0.11$ & $93.56 \pm 0.35$ & $20.45 \pm 0.23$ & $6.70 \pm 0.98$ & $178.25 \pm 0.41$ & $30.70 \pm 0.65$ & $0.33 \pm 0.03$ & $2.46 \pm 0.05$ & $1.48 \pm 0.30$ \\
\hline Gr.6 & $178.43 \pm 0.03^{*}$ & $15.30 \pm 0.26^{*}$ & $47.97 \pm 0.48^{*}$ & $56.45 \pm 0.95^{*}$ & $6.88 \pm 0.88^{*}$ & $3.45 \pm 0.22^{*}$ & $134.43 \pm 0.65^{*}$ & $27.11 \pm 0.76$ & $0.29 \pm 0.32$ & $1.80 \pm 0.20^{*}$ & $0.65 \pm 0.15^{\star}$ \\
\hline
\end{tabular}

significant $(\mathrm{P}<0.05)$ decrease in SGOT level when compared to group $2 \mathrm{NKV}$-induced animals. The percentage decrease in GOT level in VN and VN-GNP- treated animals were $32 \%$ and $41 \%$, respectively (Table 1). NKV in group 2 animals caused significant $(\mathrm{P}<0.05)$ increase in serum $\gamma$-glutamyltransferase $(\gamma$-GT) when compared to group 1 sham control animals. Treatment with ASVS and GNP caused no significant change in serum $\gamma$-GT when compared to group $2 \mathrm{NKV}$-treated animals. Treatment with VN and VN-GNP caused significant $(\mathrm{P}<0.05)$ decrease in serum $\gamma$-GT level when compared to group $2 \mathrm{NKV}$-induced animals. The percentage decrease in serum $\gamma$-GT level in VN and VN-GNP- treated animals were $56 \%$ and $69 \%$, respectively (Table 1).

NKV treatment in group 2 animals caused significant $(\mathrm{P}<0.05)$ increase in serum acid phosphatase (ACP) when compared to group 1 sham control animals. Treatment with ASVS and GNP caused no significant change in serum ACP when compared to group $2 \mathrm{NKV}$ treated animals. Treatment with VN and VN-GNP caused significant $(\mathrm{P}<0.05)$ decrease in serum ACP level when compared to group 2 $\mathrm{NKV}$-induced animals. The percentage decrease in serum ACP level in VN and VN-GNP- treated animals were $44 \%$ and $52 \%$, respectively (Table 1).

NKV treatment in group 2 animals caused significant $(\mathrm{P}<0.05)$ increase in serum alkaline phosphatase (ALP) when compared to group 1 sham control animals. Treatment with ASVS and GNP caused no significant change in serum ALP when compared to group 2 NKV-treated animals. Treatment with VN and VN-GNP caused significant $(\mathrm{P}<0.05)$ decrease in serum ALP level when compared to group $2 \mathrm{NKV}$-induced animals. The percentage decrease in serum ALP level in VN and VN-GNP- treated animals were $17 \%$ and $29 \%$, respectively (Table 1).

No significant change was observed in serum urea and serum creatinine in group 2 NKV treated animals. Treatment with ASVS, GNP, VN and VN-GNP caused no significant change in serum urea and creatinine level when compared to group $2 \mathrm{NKV}$-induced animals (Table 1). NKV treatment in group 2 animals caused significant $(\mathrm{P}<0.05)$ increase in urinary calcium when compared to group 1 sham control animals. Treatment with ASVS, GNP and VN caused no significant change in urinary calcium when compared to group 2 NKV-treated animals. Treatment with VN-GNP caused significant $(\mathrm{P}<0.05)$ decrease in urinary calcium level when compared to group $2 \mathrm{NKV}$-induced animals. The percentage decrease in urinary calcium level in VN-GNP- treated animals was 30\% (Table 1).

NKV treatment in group 2 animals caused significant $(\mathrm{P}<0.05)$ increase in urinary phosphate when compared to group 1 sham control animals. Treatment with ASVS and GNP caused no significant change in urinary phosphate when compared to group $2 \mathrm{NKV}$ treated animals. Treatment with VN and VN-GNP caused significant $(\mathrm{P}<0.05)$ decrease in urinary phosphate level when compared to group $2 \mathrm{NKV}$-induced animals. The percentage decrease in urinary phosphate level in VN and VN-GNP- treated animals were 33\% and $56 \%$, respectively (Table 1 ).

Treatment with VN-GNP significantly decreased NKV induced serum pro-inflammatory cytokines IL-1 $\beta$, IL-17 and TNF- $\alpha$ by $51.89 \%, 47.14 \%$ and $31.93 \%$ respectively in group 6 animal; whereas treatment with VN showed a reduction of serum IL-1 $\beta$, IL-17 and TNF- $\alpha$ response by $35.73 \%, 40.13 \%$ and $24.58 \%$ respectively in group 5 as compared with NKV control group 2 mice (Figures 5 and 6). In VN and VN-GNP treated group of mice, there were significant increase in serum anti-inflammatory cytokine IL-10 level as compared with NKV treated group 2 mice by $18.18 \%$ and $28.33 \%$ respectively (Figure 6). ASVS, GNP treated group of mice did not showed significant changes in serum pro and anti-inflammatory cytokines as compared with NKV treated group 2 animals.

\section{Neutralization of NKV-induced stress markers by VN-GNP}

There was significant $(\mathrm{P}<0.05)$ decrease in $\mathrm{GSH}, \mathrm{SOD}$, catalase and significant $(\mathrm{P}<0.05)$ increase in LPO in group 2 animals when

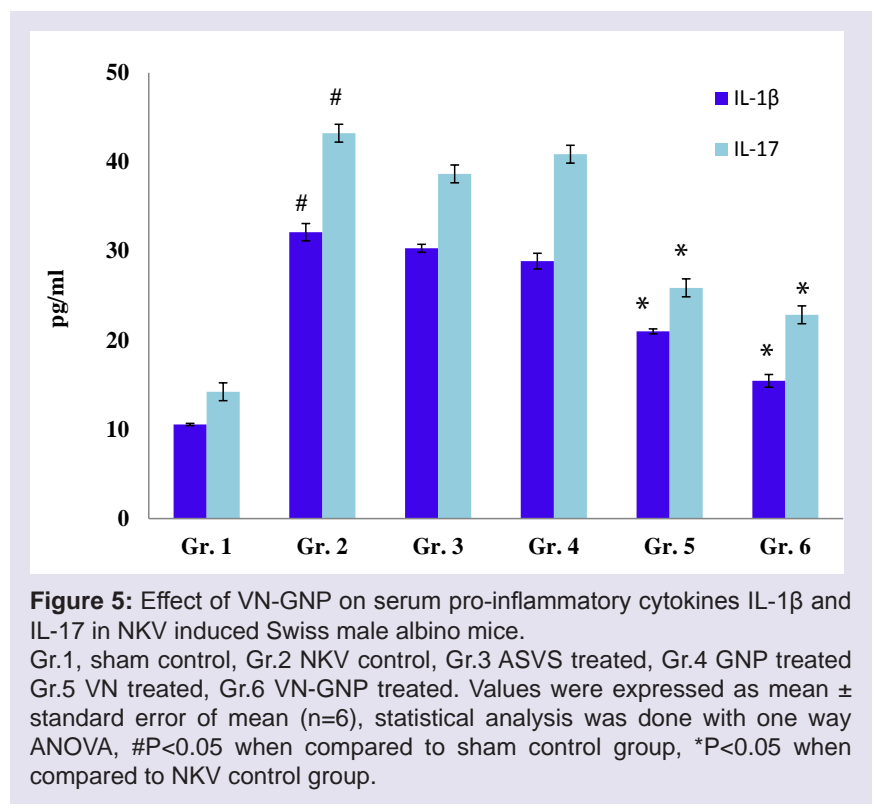


Citation: Saha K, Ghosh S, Ghosh S, Dasgupta SC, Gomes A, et al. Neutralization of Naja kaouthia Venom Induced Toxicity and Stress Response by Vitex negundo-Gold Nanoparticle (VN-GNP) in Experimental Animal Model. J Toxins. 2015;2(1):8.

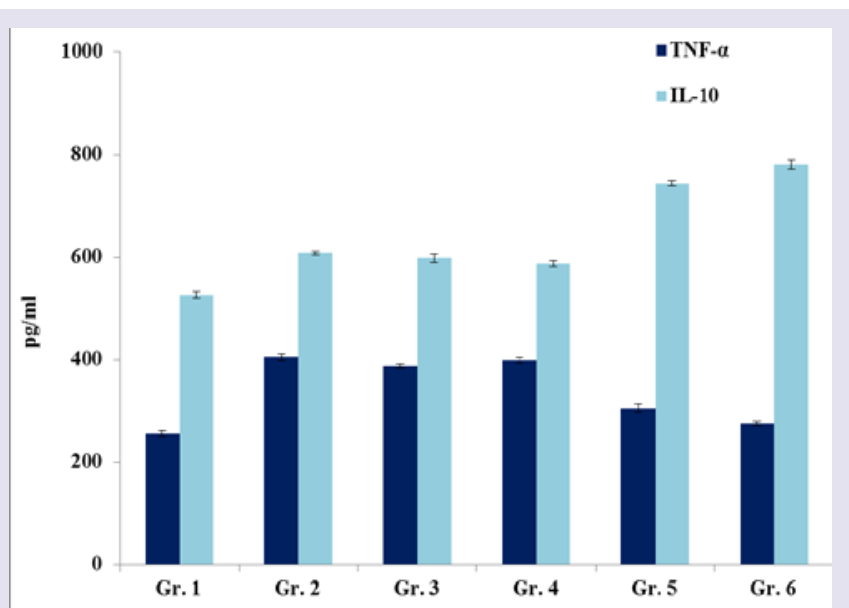

Figure 6: Effect of VN-GNP on serum pro-inflammatory and anti- inflammatory cytokines (TNF- $\alpha$ \& IL-10) in NKV induced acute exposure on Swiss male albino mice.

Gr.1, sham control, Gr.2 NKV control, Gr.3 ASVS treated, Gr.4 GNP treated Gr.5 VN treated, Gr.6 VN-GNP treated. Values were expressed as mean \pm standard error of mean $(n=6)$, statistical analysis was done with one way ANOVA, \#P<0.05 when compared to sham control group, ${ }^{*} \mathrm{P}<0.05$ when compared to NKV control group.

compared to group 1 sham control animals, indicating the occurrence of stress in NKV treated mice. Treatment with ASVS and GNP caused no significant change in GSH, SOD, catalase and LPO level when compared to group $2 \mathrm{NKV}$-treated animals. Treatment with $\mathrm{VN}$ and VN-GNP caused significant $(\mathrm{P}<0.05)$ increase in $\mathrm{GSH}$ level when compared to group $2 \mathrm{NKV}$ treated animals. The percentage increase in GSH in VN and VN-GNP- treated animals were 52\% and 59\% respectively (Table 2).

Treatment with VN and VN-GNP caused significant $(\mathrm{P}<0.05)$ increase in SOD level when compared to group $2 \mathrm{NKV}$ treated animals. The percentage increase of SOD in VN and VN-GNPtreated animals were $34 \%$ and $38 \%$ respectively (Table 2 ). Treatment with VN and VN-GNP caused significant $(\mathrm{P}<0.05)$ increase in catalase level when compared to group $2 \mathrm{NKV}$-induced animals. The percentage increase in catalase in VN and VN-GNP- treated animals were $53 \%$ and $59 \%$, respectively (Table 2). Treatment with VN and VN-GNP caused significant $(\mathrm{P}<0.05)$ decrease in LPO level when compared to group $2 \mathrm{NKV}$-induced animals. The percentage decrease in $\mathrm{LPO}$ in $\mathrm{VN}$ and VN-GNP- treated animals were $19 \%$ and $42 \%$, respectively (Table 2 ).

\section{Effect of VN-GNP on NKV induced histopathological changes}

NKV-induced liver tissue showed loss of structural integrity, cellular infiltration, necrotic lesions, hemorrhage and dilated central vein of group 2 animals. Treatment with ASVS, GNP and VN did not recover the NKV-induced histopathological changes in liver tissues in group 3, 4 and 5 respectively. Treatment with VN-GNP showed partial recovery (no haemorrhage, less necrotic lesions, less cellular infiltration) of liver in group 6 mice (Figure 7). NKV-induced kidney tissue showed congested glomerulus, cellular infiltration, inflamed and enlarged renal tubules in kidney of group 2 animals. Treatment with ASVS, GNP and VN did not recover the NKVinduced histopathological changes in kidney tissues in group 3, 4 and 5 respectively. Treatment with VN-GNP showed partial recovery (less glomerular congestion, less cellular infiltration, less tubular inflammation) of kidney tissue in group 6 mice (Figure 8).

\section{Discussion}

Owing to the limitations and side effects of ASVS, search for alternative treatment against snake envenomation is a long challenge to the toxicologists. Traditional use of natural products may be beneficial, as many herbal antagonists against snake venom have been identified in the past few decades [21]. According to Ayurveda, many herbs possess antivenom activity and may be considered as an alternate treatment of snake bite [22]. Vitex negundo is one of such herb with potent anti-snake venom activity [23]. Use of metal ashes (such as gold ash or swarnabhasma) along with herbal extracts has been reported to increase the potency of herbs in Ayurvedic formulations [13]. In the present study we have used aqueous root extract of Vitex negundo to synthesize gold nano particle, it was physico-chemically characterized and its anti-Naja kaouthia venom activity was evaluated in animal model.

The synthesized VN-GNP was violet in colour and was stable in room temperature $\left(24 \pm 2{ }^{\circ} \mathrm{C}\right)$ for 30 days. The surface distribution profile of small particles in colloidal suspension and its hydrodynamic diameter was determined by using DLS. Time dependent fluctuations in the scattering intensity arising from particles undergoing random Brownian motion was also measured by DLS. DLS data showed that the hydrodynamic diameter of VN-GNP was $80-90 \mathrm{~nm}$ with polydispersity index of 0.309 , which indicated variable range of particle size. The obtained zeta potential of VN-GNP indicated the stability of the formed nanoparticles at room temperature. In the present study, zeta potential of VN-GNP indicated moderate stability of nanoparticle. Transmission electron microscopy (TEM) image of

Table 2: Effect of VN-GNP on antioxidant parameters in NKV induced stress on Swiss male albino mice.

Gr.1, sham control, Gr.2 NKV control, Gr.3 ASVS treated, Gr.4 GNP treated Gr.5 VN treated, Gr.6 VN-GNP treated. Values were expressed as mean \pm standard error of mean $(n=6)$, statistical analysis was done with one way ANOVA, ${ }^{*} \mathrm{P}<0.05$ when compared to sham control group, ${ }^{*} \mathrm{P}<0.05$ when compared to NKV control group.

\begin{tabular}{|l|l|l|l|l|}
\hline Animal Group & \multicolumn{1}{|c|}{$\begin{array}{c}\text { GSH } \\
(\mu \mathrm{M} / \text { mg protein) }\end{array}$} & $\begin{array}{c}\text { SOD } \\
\text { (IU/mg protein) }\end{array}$ & $\begin{array}{c}\text { Catalase } \\
\text { (IU/mg Hb) }\end{array}$ & \\
\hline Gr.1 & $128.25 \pm 1.05$ & $54.36 \pm 0.05$ & $30.71 \pm 0.25$ & $7.07 \pm 0.27$ \\
\hline Gr.2 & $49.53 \pm 2.59^{\#}$ & $32.42 \pm 0.02^{\#}$ & $11.67 \pm 0.05^{\#}$ & $16.32 \pm 0.08^{\#}$ \\
Gr.3 & $52.12 \pm 0.07$ & $30.40 \pm 0.24$ & $15.59 \pm 0.23$ & $14.21 \pm 0.02$ \\
Gr.4 & $58.19 \pm 1.54$ & $35.45 \pm 0.87$ & $12.62 \pm 0.12$ & $14.89 \pm 0.68$ \\
\hline Gr.5 & $103.03 \pm 5.03^{*}$ & $48.88 \pm 0.8^{*}$ & $24.92 \pm 0.22^{*}$ & $13.29 \pm 0.08$ \\
\hline Gr.6 & $120.71 \pm 0.29^{*}$ & $52.23 \pm 0.16^{*}$ & $28.40 \pm 0.12^{*}$ & $9.54 \pm 0.10^{*}$ \\
\hline
\end{tabular}


Citation: Saha K, Ghosh S, Ghosh S, Dasgupta SC, Gomes A, et al. Neutralization of Naja kaouthia Venom Induced Toxicity and Stress Response by Vitex negundo-Gold Nanoparticle (VN-GNP) in Experimental Animal Model. J Toxins. 2015;2(1):8.
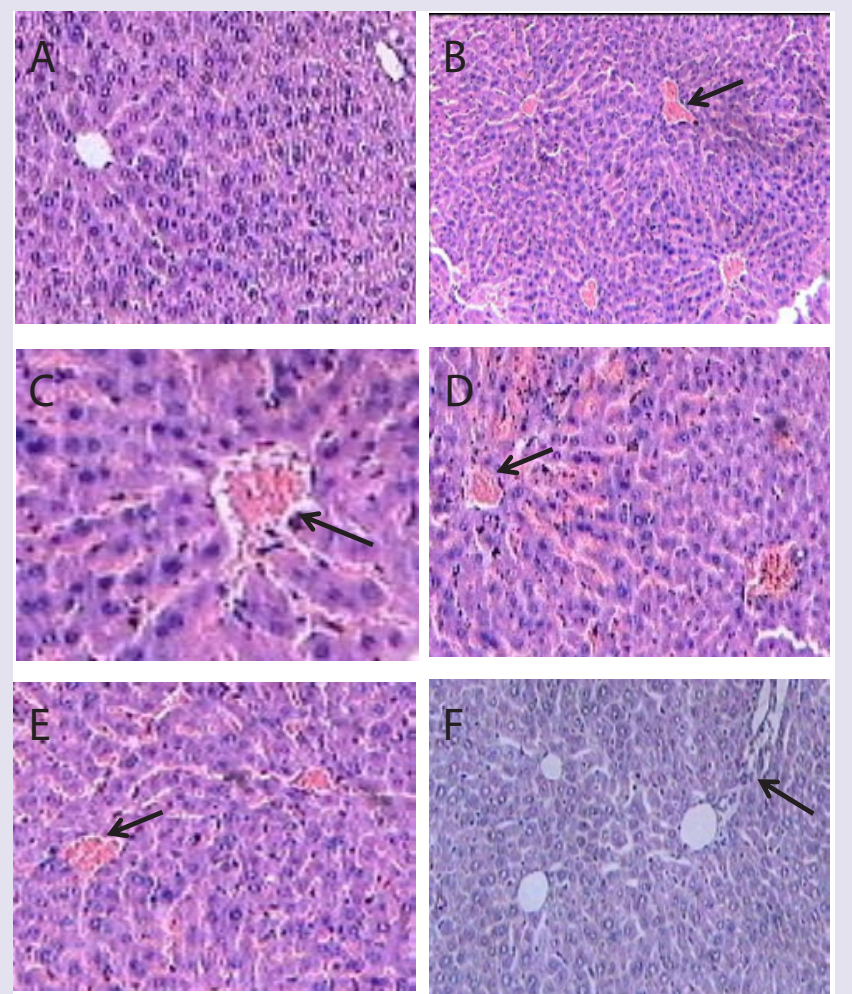

Figure 7: Effect of VN-GNP on NKV-induced liver damage in Swiss male albino mice.

A. Sham control mice, B. NKV-treated mice, C.ASVS-treated mice, D. GNPtreated mice, E. VN-treated mice, F. VN-GNP treated mice. Arrow shows hemorrhage and dialationin central vein, necrotic lesion and structura disintegrity. Treatment with VN-GNP caused partial recovery in liver histology (Magnification 150X and 300X, Haematoxyline and eosin staining).

VN-GNP indicated that there was formation of almost spherical nanoparticles having the size range of $25-40 \mathrm{~nm}$. The increased hydrodynamic diameter of VN-GNP obtained through DLS was likely due to the natural capping of VN-GNP by the organic molecules (flavonoids, triterpenoids, etc.) present in $\mathrm{VN}$ extract, which resulted the difference in size obtained from DLS and TEM. FTIR spectrum confirmed the conjugation of the gold nanoparticle with the VN extract.

In Asia, Naja kaouthia is responsible for a number of snakebites in eastern part of India, and parts of Southeast Asia like Thailand, Vietnam and Peninsular Malaysia [24]. A postsynaptic neurotoxin present in the Naja venom is the main component that binds to the nicotinic cholinergic receptor site at neuromuscular junction which produces neurotoxicity results in ptosis, opthalmoplegia with blurred vision, flaccid paralysis, loss of tendon reflex, coma, respiratory failure, local tissue swelling, tissue necrosis, inflammation, stressful conditions, myotoxicity and myonecrosis in envenomed patient. Neurotoxicity is the major cause of death following Naja kaouthia bite $[25,26]$. Proteins and peptides that exhibit diverse biochemical and pharmacological activities are the main components of snake venoms. Venoms of several cobra, including those which are sympatric have different considerable compositional, syndromic and immunological variations. Venoms of Naja kaouthia from Malaysia and Thailand exhibited substantially different degree of lethality (LD50) and response to antivenom neutralization indicating the occurrence of geographical variation in the toxin composition of this wide-ranging species [27].

In the present study, we have established myotoxicity, hepatotoxicity, nephrotoxicity, acute stress response and proinflammatory activity induced by NKV in Swiss male albino mice model. Serum creatine kinase and lactate dehydrogenase were increased in NKV induced experimental animal model due to myotoxic action of NKV. Treatment with VN-GNP significantly decreased serum creatine kinase and LDH level in group 6 animal. Treatment with VN neutralized NKV induced myotoxicity but VN-GNP showed higher neutralizing potential, indicated increased efficacy of VN after nano conjugation. ASVS treatment was unable to neutralize venom induced myotoxicity and this result was in accordance with earlier finding [28].

Hepatocellular damage releases several enzymes in circulation, which are generally known as marker of hepatotoxicity. Principal markers of hepatotoxicity are SGPT, SGOT, ACP, ALP and $\gamma$-GT. NKV-induction increased hepatic marker enzymes (SGPT, SGOT, ACP, ALP and $\gamma \mathrm{GT}$ ) in group 2 animal. Treatment with VN-GNP showed significant protection against NKV induced hepatotoxicity in group 6 mice. ASVS failed to show any protection against NKV induced hepatocellular injury markers in group 3 mice. Histo-pathological studies of liver in NKV treated group 2 showed hemorrhage in central vein, loss of structural integrity of the hepatocytes and necrotic lesion.

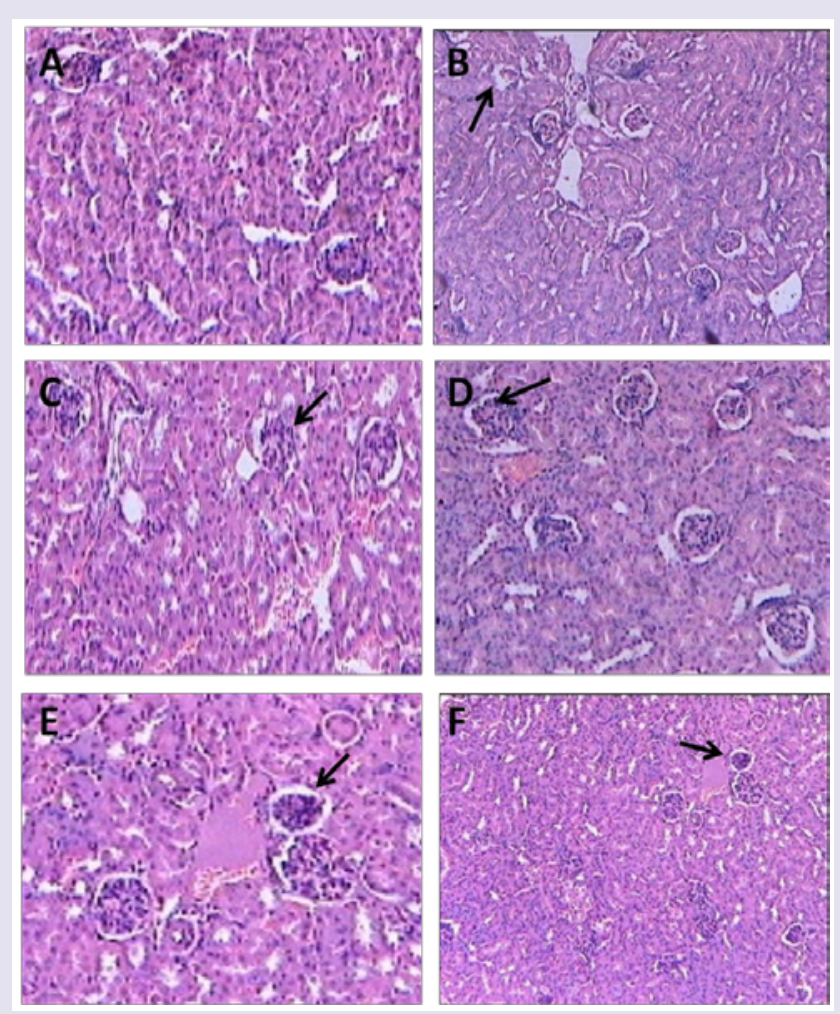

Figure 8: Effect of VN-GNP on NKV-induced kidney damage in Swiss male albino mice.

A. Sham control mice, B. NKV-treated mice, C. ASVS-treated mice, D. GNPtreated mice, E. VN-treated mice, F. VN-GNP treated mice. Arrows show congested glomerulus and increased capsular space. Treatment with VNGNP caused partial recovery in kidney histology (Magnification 150X and 300X, Haematoxyline and eosin staining). 
Citation: Saha K, Ghosh S, Ghosh S, Dasgupta SC, Gomes A, et al. Neutralization of Naja kaouthia Venom Induced Toxicity and Stress Response by Vitex negundo-Gold Nanoparticle (VN-GNP) in Experimental Animal Model. J Toxins. 2015;2(1):8.

Treatment with VN-GNP partially improved liver injury caused by NKV. Impairment of renal function occurred after envenomation of NKV in experimental animal model which resulted in high concentration of calcium and phosphorus in urine in group 2 mice. Histopathological studies of NKV induced kidney of group 2 mice showed congested glomerulus and swollen renal tubules indicating nephrotoxicity. Cobra venom-induced renal cortical toxicity has been reported earlier $[29,30]$. Treatment with ASVS, GNP and VN failed to recover the histological changes of kidney. Treatment with VN-GNP partially recovered kidney histology in group 6 animals.

The parameters of reactive oxygen species (ROS) defence mechanism such as superoxide dismutase, catalase, reduced glutathione were measured in the present study. Extent of lipid peroxidation, which is the immediate consequence of ROS generation was also examined. Patel \& Katyare has shown that stress (which can be measured by ROS production) and pro-oxidant are directly related to the pathogenesis of diseases [31]. Cobra envenomation causes a decrease in antioxidant parameters and increase in pro-oxidants [32]. In the present study, Group 2 venom control animals showed a significant increase in prooxidant and decrease in antioxidant parameters when compared to group 1 sham control mice. Reduced glutathione $(\mathrm{GSH})$ is an antioxidant which scavenges free radical and itself oxidized to form GS-SG. GSH in NKV treated group 2 animals decreased significantly when compared with sham control group, which suggest the increased production of oxidative stress. VN-GNP treatment caused significant increase in GSH level in group 6 animal. Superoxide anion is scavenged into hydrogen peroxide by superoxide dismutase (SOD) activity. Toxic peroxides in cell are eliminated by catalase which forms non-toxic water and oxygen. SOD and catalase scavenge free radicals generated by oxidative stress [33]. It was observed that in NKV treated group 2 mice, there was significant decrease of SOD and catalase level when compared with sham control group 1 animals, which indicated increased production of ROS. Treatment with VN-GNP and VN increased SOD and catalase activity. VN-GNP treatment showed higher protection than that of VN treated group 5 animals. Cell membrane rupture leads to cell lysis after oxidization of cell membrane due to lipid peroxidation [31]. Significant lipid peroxidation activity was observed in NKV treated group 2 animals, when compared with sham control group. This study indicated that there was significant peroxidation of plasma membrane in experimental Naja kaouthia envenomation. After VNGNP treatment, membrane peroxidation was reduced, indicating protection against stress by VN-GNP treatment. ASVS, GNP and $\mathrm{VN}$ failed to offer significant protection in group 3, 4 and 5 mice, respectively.

After treatment with NKV in group 2 mice, there were high levels of pro-inflammatory cytokines such as TNF- $\alpha$, IL- $1 \beta$ and IL17. Experimental envenomation by NKV may activate macrophages which inturn induces the release of TNF- $\alpha$ and IL-1 $\beta$. Activated T-cells releases IL-17 which may stimulate the release of TNF- $\alpha$ and IL-1 $\beta$ from macrophages. Treatment with VN-GNP significantly decreased the release of pro-inflammatory cytokines like TNF- $\alpha$, IL$1 \beta$ and IL-17, and increased the level of anti-inflammatory cytokines like IL-10, when compared with NKV treated group 2 mice, indicating that $\mathrm{VN}-\mathrm{GNP}$ restored the balance of the cytokines.
The herb VN extract have been reported to contain several bioactive compounds (flavonoids, triteponoids, vitexin, isovitexin etc) which combine with gold nanoparticle providing stability of VNGNP) [34]. It also helped to target the VN-GNP at the cellular and molecular level for its activation through marker enzymes, pro and anti inflammatory cytokines. However, it was not clear whether VNGNP acted at the receptor target molecules to show its anti venom effects. Further studies on the molecular mechanism of action of VNGNP are warranted before clinical trials.

\section{Conclusion}

Present study indicated that Vitex negundo gold nanoparticle (VN-GNP) significantly antagonized toxicity, acute stress, proinflammatory cytokines response, increased anti-inflammatory cytokine response induced by Naja kaouthia venom in Swiss male albino mice model. VN-GNP also had protective effects against Naja kaouthia venom induced histopathological changes in liver and kidney tissues. It can be concluded that Vitex negundo gold nanoparticle (VN-GNP) may provide supplementary strategy in attenuating toxicity, cellular stress response in addition to standard antivenom against snake venom in the near future.

\section{References}

1. Gupta YK, Peshin SS (2014) Snake bite in India: current scenario of an old problem. J Clin Toxicol 4: 182

2. World Health Organization (2007) Rabies and envenomings: a neglected public health issue (WHO, Geneva).

3. Alirol E, Sharma SK, Bawaskar HS, Kuch U, Chappuis F (2010) Snake bite in South Asia: a review. PLoS Negl Trop Dis 4: e603.

4. Das D, Urs N, Hiremath V, Vishwanath BS, Doley R (2013) Biochemical and biological characterization of Naja kaouthia venom from North-East India and its neutralization by polyvalent antivenom. J Venom Res 4: 31-38.

5. Offerman SR, Smith TS, Derlet RW (2001) Does the aggressive use of polyvalent antivenin for rattlesnake bites result in serious acute side effects? West J Med 175: 88-91.

6. Lalloo DG, Theakston RD (2003) Snake antivenoms. J Toxicol Clin Toxicol 41: 277-290.

7. Williams DJ, Jensen SD, Nimorakiotakis B, Muller R, Winkel KD (2007) Antivenom use, premedication and early adverse reactions in the management of snake bites in rural Papua New Guinea. Toxicon 49: 780792.

8. Chippaux JP, Goyffon M (1991) Antivenom serotherapy: its applications, its limitations, its future. Bull Soc Pathol Exot 84: 286-297.

9. Santhosh MS, Sundaram MS, Sunitha K, Kemparaju K, Girish KS (2013) Viper venom-induced oxidative stress and activation of inflammatory cytokines: a therapeutic approach for overlooked issues of snakebite management. Inflamm Res 62: 721-731.

10. Samy RP, Thwin MM, Gopalakrishnakone P, Ignacimuthu S (2008) Ethnobotanical survey of folk plants for the treatment of snakebites in Southern part of Tamilnadu, India. J Ethnopharmacol 115: 302-312.

11. Alam MI, Gomes A (2003) Snake venom neutralization by Indian medicinal plants (Vitex negundo and Emblica officinalis) root extracts. J Ethnopharmacol 86: $75-80$.

12. Durairaj B, Muthu SK, Shreedharj K (2014) In vitro antivenom and antioxidant potential of Vitex negundo leaves (green and blue) against Russell's viper (Daboia russelli) and Indian cobra (Naja naja) venom. Eur J Exp Biol 4: 207 219.

13. Gomes A, Ghosh S, Sengupta J, Datta P, Gomes A(2014) Herbonanoceuticals: a new step towards herbal therapeutics. Med Aromat Plants 3: 1-9. 
Citation: Saha K, Ghosh S, Ghosh S, Dasgupta SC, Gomes A, et al. Neutralization of Naja kaouthia Venom Induced Toxicity and Stress Response by Vitex negundo-Gold Nanoparticle (VN-GNP) in Experimental Animal Model. J Toxins. 2015;2(1):8.

14. Gomes A, Sengupta J, Ghosh S, Gomes A (2015) Application of gold nanoparticle conjugation with 2-hydroxy-4-methoxy benzoic acid (HMBA) from Hemidesmus indicus root enhancing neutralization of snake (Viper) venom activity. J Nanosci Nanotechnol (In Press).

15. Fiske $\mathrm{CH}$, Subbarow $\mathrm{Y}(1925)$ The colorimetric determination of phosphorous. J Biol Chem 66: 375-400.

16. Ellman GL (1959) Tissue sulfhydrayl groups. Arch Biochem Biophys 82: 70 -77 .

17. Pryor WA (1973) Free radical reactions and their importance in biochemical systems. Fed Proc 32: 1862-1869.

18. Buege JA, Aust SD (1978) Microsomal lipid peroxidation. Methods Enzymol 52: 302-310

19. Beers RF, Sizer IW (1952) A spectrophotometric method for measuring the breakdown of hydrogen peroxide by catalase. J Biol Chem 95: 133-140.

20. Lowry OH, Rosebrough NJ, Farr AL, Randall RJ (1951) Protein measurement with the folin phenol reagent. J Biol Chem 193: 265-275.

21. Devi CM, Bai MV, Lal AV, Umashankar PR, Krishnan LK (2002) An improved method for isolation of anti-viper venom antibodies from chicken egg yolk. J Biochem Biophys Methods 18: 129-138.

22. Lakshmi V, Lakshmi T (2013) Antivenom activity of traditional herbal drug: an update. Int Res J Pharm 4: 1-3.

23. Ladda PL, Magdum CS (2012) Vitex negundo Linn: ethnobotany phytochemistry and pharmacology- a review. Int J Adv Pharm Biol Chem 1 : 111-120.

24. Wuster W, Thorpe RS (1991) Asiatic cobras: Systematics and snakebite Experientia 47: 205-209.
25. Wongtongkam N, Wilde $\mathrm{H}$, Amorn CS, Ratnabanangkoon K (2005) Study of Thai cobra (Naja kaouthia) bites in Thailand. Military Med 170: 336-341.

26. Bernheim A, Lorenzetti E, Licht A, Markwalder K, Schneemann M (2001) Three cases of severe neurotoxicity after cobra bite (Naja kaouthia). Swiss Med Wkly 131: 227-228.

27. Tan KY, Tan CH, Fung SY, Tan NH (2015) Venomics, lethality and neutralization of Naja kaouthia (monocled cobra) venoms from three different geographical regions of Southeast Asia. J Proteomics 120: 105-125.

28. Isbister GK, Halkidis L, O'Leary MA, Whitaker R, Cullen P, (2010) Human anti-snake venom IgG antibodies in a previously bitten snake-handler, but no protection against local envenoming. Toxicon 55: 646-649.

29. Rahmy TR (2001) Action of cobra venom on the renal cortical tissues: electron microscopic studies. J Venom Anim Toxins 7: 85-112.

30. Hemmaid KZ (2010) Histological and ultrastructural alterations in the renal cortex of rats induced by Egyptian cobra (Naja haje) crude venom. Egypt J Exp Biol 6: 319-330.

31. Patel SP, Katyare SS (2006) A comparative study of reactive oxygen species (ROS) related parameters in rat tissues. Indian J Clin Biochem 21: 48-53.

32. Tohamy AA, Mohamed AF, Moneim AE, Diab MS (2014) Biological effects of Naja haje crude venom on the hepatic and renal tissues of mice. J King Saud Univ Sci 26: 205-212.

33. Ghosh S, Sengupta J, Datta P, Gomes A (2014) Hematopoietic and antioxidant activities of gold nanoparticle synthesized by aqueous extract of fenugreek (Trigonella foenum-graecum) seed. Adv Sci Eng Med 6: 546-552.

34. Vishwanathan AS, Basavaraju R (2010) A review on Vitex negundo L. - a medicinally important plant. EJBS 3: 30-42.

\section{Acknowledgements}

The authors thank UGC, New Delhi, Government of India for providing partial financial assistance and UGC-BSR fellowship to Prof. Antony Gomes. 